\title{
Implicit and Explicit Gender Stereotypes at the Bargaining Table: Male Counterparts' Stereotypes Predict Women's Lower Performance in Dyadic Face-to-Face Negotiations
}

\author{
Vaani Pardal ${ }^{1,2} \cdot$ Madeliene Alger $^{3}$ - Ioana Latu ${ }^{4}$ \\ Published online: 8 January 2020 \\ (C) The Author(s) 2020
}

\begin{abstract}
In every major occupational group and at every level of educational attainment, U.S. women earn less than men (Carnevale et al. 2018). Besides a component explained by objective factors (e.g., hours worked, occupation, experience), the gender wage gap includes a large component unexplained by objective factors. This latter component may be attributed, at least in part, to factors such as gender stereotyping and discrimination. In one study, we focus specifically on negotiation partners' gender stereotypes by investigating mock face-to-face negotiations around salary and benefits mimicking real world job settings. We specifically investigated whether U.S. women's $(n=83)$ negotiation performance was predicted by their negotiation counterparts' implicit and explicit gender stereotypes and whether these effects depended on the gender of the negotiation counterpart and their randomly assigned power role in the negotiation (recruiter vs. candidate). Overall, our findings suggest that regardless of women's power role in negotiations, women's lower performance is predicted by their male counterparts' higher implicit stereotypes. For female recruiters, this effect is further qualified by their male counterparts' explicit stereotypes. Our discussion explores how temporary power roles contribute to the expression of implicit and explicit gender stereotypes in negotiations. We also discuss practice implications for reducing negative effects of stereotypes on women's negotiation performance.
\end{abstract}

Keywords Gender gap $\cdot$ Implicit bias $\cdot$ Sexism $\cdot$ Negotiation $\cdot$ Bargaining $\cdot$ Power

Despite growing impetus and numerous efforts to promote gender equality, women continue to earn less than men in nearly every profession (Carnevale et al. 2018), yielding an average gender pay gap of $16.6 \%$ worldwide, with some countries showing gaps of up to $47.2 \%$ (International Labour Organisation 2019). Not only is progress in narrowing the gender wage gap very slow, but also future projections

Electronic supplementary material The online version of this article (https://doi.org/10.1007/s11199-019-01112-1) contains supplementary material, which is available to authorized users.

Ioana Latu

i.latu@qub.ac.uk

1 Temple University, Philadelphia, PA, USA

2 Department of Psychology, Rutgers University Camden, Camden, NJ, USA

3 Senator Walter Rand Institute for Public Affairs, Rutgers University, Camden, NJ, USA

4 Queen's University, 18-30 Malone Road, Belfast BT9 5BN, UK indicate that unless accelerated efforts are made to attain equality, it will currently take 202 years to close this gap (World Economic Forum 2018).

In order to create targeted interventions to close the gender wage gap, it is important to uncover the factors that contribute to income inequality between men and women. There are several objective factors that contribute to the gender wage gap, such as differences in hours worked, experience and level of education (O'Neill 2003). However, even after controlling for these factors, the gender wage gap persists, suggesting there is a relatively large unexplained component. For example, $63.9 \%$ of the gap is unexplained in the United Kingdom (Office for National Statistics 2018). It is likely that beyond objective factors, social factors derived from ubiquitous gender roles may partially explain the gap. Indeed, some studies suggest that a portion of the wage gap is likely attributed to gender stereotypes and discrimination (Blau \& Kahn 2017; Kray \& Thompson 2004).

In the current research we aim to understand whether and how these gender stereotypes manifest themselves in initial salary negotiations, thus partially contributing to pay disparity 
between women and men. Research suggests that men generally perform better than women in bilateral bargaining situations, with some exceptions (Mazei et al. 2015). This gender gap in negotiation performance may be important in explaining the gender wage gap, particularly in the context of salary negotiations. In most organizations, salary hikes are calculated as a percentage of one's current salary and, therefore, even nominal differences in starting salaries may have a compounding effect over many years, thus greatly widening the gender gap overall (Babcock \& Laschever 2009). We investigate whether positive or negative beliefs (stereotypes) about the negotiation ability of one or both genders permeate salary negotiations contributing to gender differences in objective performance. Women's performance may be associated with their counterparts' explicit gender stereotypes, which are typically captured through self-reports as well as by implicit stereotypes which are usually activated with relatively lower conscious awareness (Latu et al. 2015).

Taking into account this distinction between explicit and implicit stereotyping, we seek to answer three main questions. First, to what extent do negotiation counterparts' implicit and explicit gender stereotypes predict women's objective salary outcomes in actual face-to-face interactions? Second, are women similarly influenced by their counterparts' stereotypic beliefs depending on the gender of their negotiation counterpart? Third, how does the power role of the negotiation counterpart (lower/candidate vs. higher/recruiter) moderate the effects of their gender stereotypic beliefs on women's performance? Overall, whereas most studies have focused on factors intrinsic to women such as their skills, personality, self-concept, and aspirations in the context of negotiations (Amanatullah \& Morris 2010, Babcock \& Laschever 2009; Kray et al. 2001), we aim to understand how factors outside women's controlsuch as their counterparts' stereotypes, gender, and power role-may undermine their performance at the bargaining table and contribute to the gender wage gap.

\section{Gender in Negotiations}

Recent meta-analytic evidence shows that men generally negotiate better outcomes for themselves in bilateral bargaining situations, unless certain conditions are satisfied (Mazei et al. 2015). Moreover, with respect to salary negotiations, some evidence suggests that women achieve lower outcomes because they come to the bargaining table with lower aspirations (Kray et al. 2001) and are reluctant to initiate negotiations (Babcock \& Laschever 2009).

Consistent with role congruity theory (Eagly \& Karau 2002), these gender differences in negotiation behaviors and outcomes can be explained, at least in part, by workplace biases such as stereotypes and discrimination (Kray \&
Thompson 2004). These workplace gender stereotypes generally associate women with weakness, emotionality, and being accommodating, and men with strength, rationality, and assertiveness (Spence et al. 1974) - traits that are highly consequential for negotiation outcomes. These stereotypes can impact women's negotiation performance, consistent with research on stereotype threat (Steele 1997), which suggests that the mere awareness of negative stereotypes associated with performance of one's in-group in a given domain can impede their actual performance. Indeed, stereotype threat influenced women's performance in mixed-gender negotiations. For example, although men and women performed at a similar level in a baseline negotiation, men outperformed women when gender stereotypes were linked to negotiation success and the task was framed as a diagnostic test of their actual negotiation abilities (as opposed to being framed as a simple learning tool), thus inducing stereotype threat (Kray et al. 2001). Moreover, in one study, negotiation ability was found to be influenced by women's fear of backlash for violating gender stereotypes by acting assertively, contributing to a gender negotiation gap (Amanatullah \& Morris 2010). However, this difference was eliminated when women negotiated on behalf of a third party. The finding that women feel confident being assertive (e.g. asking for concessions; making positional demands) when negotiating on behalf of another person suggests that it is the fear of backlash, and not a lower innate ability to negotiate, that drives lowered outcomes for women.

To summarize, there is evidence that the activation of women's own gender stereotypes can impede their negotiation performance through the process of stereotype threat (Kray et al. 2001; Tellhed \& Björklund 2011) or by anticipating negative reactions and backlash based on gender stereotypes (Amanatullah \& Morris 2010). However, there is no research, to our knowledge, that investigated how the actual gender stereotypes of negotiation counterparts may relate to women's negotiation performance in actual face-to-face negotiations. Importantly, we further distinguish between explicit and implicit stereotypes and explore whether women's negotiation outcomes are predicted by their negotiation counterparts' explicit and/or implicit gender stereotypes.

\section{Gender Stereotypes in Face-to-Face Negotiations}

Stereotypes are cognitive constructions that contain overgeneralized assumptions about members of social groups. According to dual-process models (Fazio \& Towles-Schwen 1999; Fiske \& Neuberg 1990; Gawronski \& Bodenhausen 2006), stereotypes may fall on a continuum between an explicit pole and implicit pole. Whereas implicit stereotypes tend to be associated with automatic processing, thus being 
activated with more cognitive efficiency and less awareness, intention, and control, explicit stereotypes are associated with more controlled processing, thus being activated more purposefully (Bargh 1994; Fazio \& Olson 2003).

As global efforts to achieve gender equality have gained traction over the past few decades, explicit stereotypes about women in the workplace have become more positive (Koenig et al. 2011; Stoker et al. 2012). However, such positive explicit stereotypes may be the result of social desirability concerns, that is, people not being willing to report negative thoughts about women in workplace settings. Indeed, when measuring implicit stereotypes, which bypass (to a certain extent) such social desirability concerns, negative views about women in the workplace continue to exist (Latu et al. 2011) and to disadvantage women in stereotypically male domains such as managerial decisions and job interviews (Latu et al. 2015, Latu et al. 2011). In other words, some individuals may have egalitarian views toward others at an explicit level, but they may continue to hold negative beliefs at an implicit level (Dovidio et al. 2001). In the realm of racial stereotypes, Dovidio and Gaertner (2004) describe individuals showing this combination of low explicit and high implicit stereotypes as aversive racists: good intentioned people who hold egalitarian beliefs and consciously support principles of gender equality, but simultaneously hold conflicting negative feelings and beliefs about racial/ethnic minorities at an implicit level.

Similarly, in the realm of gender, explicit and implicit gender managerial stereotypes can diverge (Latu et al. 2011), suggesting the existence of aversive sexists who hold inconsistent explicit versus implicit gender beliefs. For example, participants tended to associate women, more than men, with competent managerial traits at the explicit level. However, at the implicit level, the pattern of associations was reversed, such that women were more likely to be associated with incompetent manager traits compared to men. These associations were particularly strong for male participants.

Importantly, contrasting implicit and explicit stereotypes may interact to predict outcomes in face-to-face interactions. Evidence for this effect comes from both interracial and mixed-gender interactions. For example, when investigating the effects of White physicians' racial bias on Black patients, Penner and colleagues (Penner et al. 2010) found that Black patients reacted most negatively when they interacted with a White physician who was high in implicit but low in explicit bias (aversive racist). Similarly, within mixed-gender job interviews, Latu and colleagues (Latu et al. 2015) showed that male interviewers' explicit and implicit stereotypes interacted to predict lower performance of women applicants. Female job candidates' performance (as rated by trained external evaluators) suffered the most when they were interviewed by male interviewers who were, at the same time, high in implicit but low in explicit gender stereotypes (aversive sexist). For both racial and gender biases, these findings are explained by the different behavioral manifestations of implicit versus explicit biases. Given their controlled nature, explicit stereotypes tend to be more closely associated with controlled (verbal) behaviors and implicit biases with automatic (nonverbal) behaviors (Dovidio et al. 2002). Within face-to-face interactions, the conflicting verbal and nonverbal cues from aversive racists/ sexists may be cognitively taxing for the targets of those biases, thus hindering their performance.

In the current study we wish to expand this prior research by investigating the interactive roles of implicit and explicit gender stereotypes on face-to-face negotiations, while concomitantly investigating, for the first time to our knowledge, the influence of additional contextual factors such as gender and power roles. Drawing from the racial bias literature (Penner et al. 2010) as well as job interview research (Latu et al. 2015), we suggest that negotiating counterparts' implicit and explicit stereotypes will act in conjunction to predict women's ability to claim value at the bargaining table. More specifically, we reason that women's negotiated outcomes may be a function of their negotiation counterparts' explicit and implicit gender stereotypes, and we expect women's performance to suffer the most when they negotiate with men who are simultaneously high in implicit, but low in explicit, stereotypes (i.e., aversive sexists).

Although our predicted finding would replicate the findings from the job interview research, we believe, for several reasons, that face-to-face workplace negotiations offer a valuable added opportunity to study how gender stereotypes and expectations may influence the behavior of women as targets of these biases. First, "negotiation occurs whenever people cannot achieve their own goals without the cooperation of others" (Thompson et al. 2010, p. 491). In a face-to-face interaction, individuals are simultaneously perceivers of counterparts' behaviors, targets of counterparts' perceptions, and perceivers of their own behaviors (Deaux \& Major 1987; Bowles \& Flynn 2010). Because face-to-face interactions necessitate greater social presence, gender stereotypes in the form of self-concept and behavioral expectancies may get transmitted with relative ease within the communication to influence negotiators' behavior and outcomes. In fact, gender stereotypic effects on women's behavior have been found to be the strongest while communicating face-to-face, in comparison to virtual channels (Stuhlmacher et al. 2007). Moreover, face-to-face negotiations afford goal communication not just through verbal signals, but also through nonverbal cues such as expressions, gestures, and eye movements, thus being particularly appropriate for capturing the influence of both implicit and explicit stereotypes.

Second, face-to-face negotiation interactions are a useful medium for investigating the role of gender stereotypes on women's performance because they allow for precise and objective quantification of women's performance (e.g., level of 
salary, signing bonus, number of vacation days). Although the influences of implicit and explicit gender stereotypes have been documented in face-to-face interactions such as job interviews (Latu et al. 2015), performance measures may have been influenced by raters' own gender stereotypes. Given the quantitative nature of negotiation outcomes, performance is objectively and realistically measured. As such, we are both replicating and extending the findings of Latu et al. (2015) to objective measures of performance afforded by a face-to-face negotiation situation.

Additionally, certain situational factors can moderate the extent to which women perform less well than men in negotiations (Mazei et al. 2015), but also the extent to which gender roles and stereotypes are more or less salient (Eagly \& Karau 2002). Therefore, as a novel contribution beyond studies on awareness of gender stereotypes in negotiation (Amanatullah \& Morris 2010; Kray et al. 2001; Tellhed \& Björklund 2011), we will not only investigate whether women's performance is predicted by their negotiation counterparts' explicit and implicit gender stereotypes, but also examine whether these effects are further qualified by the counterpart's characteristics such as their gender and power roles within the negotiation (lower/candidate vs. higher/recruiter). We therefore will expand the scope of the present study to include the role of contextual factors in predicting the gender negotiation gap.

\section{Contextual Factors: Negotiating Counterpart's Gender}

In another advancement from the existing literature, beyond understanding how implicit and explicit stereotypes may impede women's objective negotiation performance, we also seek to clarify whether the gender of the counterpart moderates this effect. Latu and colleagues (Latu et al. 2015) studied performance in mixed-gender job interviews, where the interviewers were always men and the applicants were always women. It is not clear whether female interviewers' gender stereotypes would similarly influence women's performance during workplace negotiations and, if so, in what way. The current research will investigate how explicit and implicit gender stereotypes coming from a male versus female negotiation counterpart may influence women's performance during workplace negotiations. We will compare mixed-gender (woman-man), and same-gender (woman-woman) dyads to parse out the role of negotiating counterparts' gender on women's ability to claim value for themselves at the bargaining table.

Gender stereotypes are closely linked to the status one holds in society (Ridgeway 2011), with men being ascribed a higher status than women (Miles \& Clenney 2010; Ridgeway \& Diekema 1992). Researchers suggest that differences in social status can predict negotiation outcomes (Kray \& Thompson 2004; Miles \& Clenney 2010). High status individuals are more influential in negotiations because they are perceived as more competent and their actions are seen as more legitimate. Salary negotiations are seen as a stereotypically masculine domain, where men are associated more strongly than women with effective negotiator traits (Kray \& Thompson 2004; Spence et al. 1974). As a consequence, men tend to have relatively more power compared to women due to their higher perceived competence and legitimacy of ideas, inputs, and arguments (Miles \& Clenney 2010). This type of societal power and status are important: Individuals lower in power are more likely to attend to signals from those higher in power (than vice-versa) in an attempt to predict and control the reactions of higher power individuals who control resources (Fiske 1993). As a consequence, we predict that women would be more influenced by the expectations and beliefs of their male negotiation partners rather than those of their female partners.

Moreover, gender differences in outcomes vary based on the salience of gender stereotypes in a given situation (Kray \& Thompson 2004; Kray et al. 2001). According to Cook (1994), gender roles (stereotypes) can be automatically activated in an interaction, but some situations can moderate their salience (Eagly \& Karau 2002). For example, the status difference in a female-male dyad is more salient than in a femalefemale dyad (Bowles et al. 2007; Deaux \& Major 1987; Kray $\&$ Thompson 2004). Presumably, the gender status difference in a female-male dyad may make male advantage/female disadvantage more apparent within the negotiation (vs. female counterparts in a woman-woman dyad). This argument strengthens our prediction that women's negotiation performance will be more strongly predicted by their male rather than female negotiation counterparts' implicit and explicit gender stereotypes.

\section{Contextual Factors: The Power Role in Negotiation}

Although research on both interracial interactions and mixedgender interactions shows that implicit and explicit stereotypes often interact to predict behaviors and outcomes (Latu et al. 2015; Penner et al. 2010), little is known about how certain situational factors may moderate the relative influence of implicit and explicit stereotypes in determining outcomes for the targets of these biases in workplace interactions. An important (and commonly encountered) contextual factor that may contribute to gender differences across the bargaining table is the situational power available to the negotiators. Previous studies have indicated that exuding dominance can increase one's success in a negotiation, suggesting that dominance has a pivotal role at the bargaining table (Thompson 
et al. 2010). In negotiations, expressing dominance can increase a negotiator's ability to claim value (Belkin et al. 2013).

Although power and dominance can be dispositional traits, they can also be related to situational factors, such as a person's status or role, which can therein serve as relative power (Kray \& Thompson 2004; Pinkley et al. 1994). Power is defined as the ability to control resources, one's own and others', without social interference (Galinsky et al. 2003a). Within employment negotiations, given that power is defined as control over resources and outcomes, the consensus is that recruiters, who are offering the job and associated resources, are generally more powerful than candidates, who are seeking to obtain the job and associated resources (Galinsky et al. 2003b). As a result, recruiters generally tend to negotiate better outcomes for themselves compared to candidates (Pinkley et al. 1994).

How does the power role moderate the influence of counterparts' implicit and explicit stereotypes on women's negotiation performance? Some studies suggest that power increases reliance on automatic rather than controlled processing in social cognition (Keltner et al. 2003). In other words, being in a powerful role may reduce people's need to process individual information about others in a controlled manner (Goodwin et al. 2000), such that they would rely more on heuristic/automatic judgments of others (corresponding to implicit stereotypes) compared to controlled judgments (corresponding to explicit stereotypes). As such, when the non-stigmatized have situational power (i.e., male recruiters in the negotiation), their implicit bias toward stigmatized groups is enhanced (Richeson \& Ambady 2003; Schmid \& Amodio 2017). We propose to extend our investigation to the interaction partner, and we suggest that if being in a power position enhances one's reliance on implicit rather than explicit beliefs in interpersonal interactions, outcomes for women candidates would more likely be predicted by male recruiters' implicit rather than their explicit beliefs. In other words, recruiters' explicit stereotypes would be inconsequential, and thus they would not interact with recruiters' implicit stereotypes to predict outcomes.

On the contrary, when negotiators are in a low power role (i.e., when the counterpart is in the candidate role), they are also likely processing individuating information about their negotiation partner in a controlled way (corresponding to explicit stereotypes). Because of this processing, it is likely that a low-power negotiator's behavior within the interaction would be driven by both their explicit and implicit gender stereotypes, which we expect would interact to influence women's performance.

To summarize, we predict that female candidates' negotiation performance will be predicted by the male (but not female) recruiters' implicit stereotypes only, given their higher power within the negotiation. In contrast, female recruiters' negotiation performance will be predicted by the interaction of implicit and explicit stereotypes of the male (but not the female) candidates, given their lower power role within the negotiation.

However, we caution that an alternative hypothesis regarding the role of situational power can be formulated. In interracial and mixed-gender interaction studies (Latu et al. 2015; Penner et al. 2010), although power was not explicitly manipulated, a power differential is assumed to have existed between the stigmatized and the non-stigmatized groups. Men and Whites were placed in higher power roles (interviewers and physicians, respectively) relative to women and Blacks who were placed in lower power roles (interviewees and patients, respectively). In these studies, both male interviewers' and White physicians' implicit and explicit stereotypes interacted to predict outcomes for women applicants and Black patients, possibly suggesting that situational power may not be a significant situational moderator in this context. If this were the case, then women's performance would be predicted by their counterparts' explicit and implicit gender stereotypes, irrespective of their power role. However, we should note that this prediction is not rooted in theory but rather derived from the two existing empirical findings available, in which power was not manipulated or even conceptualized per se. As such, although we acknowledge the potential of this competing hypothesis, we primarily put forward the initial hypothesis according to which power role would moderate the relationship between stereotypes and performance.

\section{The Current Study}

The goal of the current research was to examine how stereotypes may act as barriers for women in face-to-face employment negotiations. We set out to investigate whether women's negotiation performance is predicted by their negotiation counterparts' implicit and explicit gender stereotypes and whether these effects are moderated by the counterpart's gender and negotiator role. The present research question was addressed in a two-phase study. In the first phase, we measured participants' implicit and explicit gender-negotiator stereotypes by assessing the extent to which women and men are implicitly and explicitly associated with good (strong, dominant, assertive, rational, active, effective) and bad (weak, submissive, accommodating, emotional, passive, ineffective) negotiator traits. In the second, seemingly unrelated phase, participants engaged in a face-to-face, mock negotiation for a start-up package for a managerial position. The paradigm was adapted from Pinkley et al. (1994) and involved negotiating for four items: salary, vacation days, signing bonus, and location. Female participants were randomly assigned to either the recruiter or candidate role and to negotiate either with a male or female counterpart. We were able to obtain an 
objective negotiation outcome for both candidates and recruiters (i.e., the total points each participant obtained across all negotiation items) and investigated the extent to which this objective negotiation outcome for female participants was predicted by their negotiation counterparts' implicit and explicit gender stereotypes, gender, and power role within the negotiation. Importantly, because we wanted to capture the effects of gender stereotypes within the face-to-face interaction, above and beyond any expectations prior to the negotiation interaction (Amanatullah \& Morris 2010), we measured and controlled for the female targets' ideal negotiation outcome before the actual negotiation.

To summarize, drawing from the literature on power and stereotyping (Richeson \& Ambady 2003; Schmid \& Amodio 2017), we proposed that male counterparts' power role will moderate the relative influence of their implicit and explicit gender stereotypes to predict outcomes for women. More specifically, we propose that female candidates' negotiation outcomes will be predicted by the male (but not female) recruiters' implicit rather than explicit gender stereotypes, whereas female recruiters' negotiation outcomes will be predicted by the male (but not female) candidates' explicit and implicit gender stereotypes.

\section{Method}

\section{Design and Participants}

Although subsequent analyses showed that the present data can be treated at an individual level, data collection was conducted in female-male and female-female dyads. The focal participants were all women, with men serving as randomly assigned negotiation counterparts in one condition. The study included three quasi-independent variables (i.e., a negotiation counterpart's gender, implicit stereotypes, and explicit stereotypes), one true independent variable (i.e., role assignment as either the candidate or the recruiter in the negotiation task), and one dependent variable (i.e., women's performance on the negotiation task, which combined outcomes involving salary, vacation days, a signing bonus, and job location).

Focal participants were 83 women recruited from an introductory psychology course at a U.S. university. Although 101 women were initially recruited, 18 women were excluded because of missing data $(n=12)$ or because they failed to reach agreement on the negotiation task $(n=6)$. Additionally, 39 men were tested for their implicit and explicit stereotyping and served as negotiation counterparts for women who had been randomly assigned to the experimental condition of having a male negotiation counterpart.

Overall then, data collected involved 39 female-male pairs and 44 female-female pairs in which both women served as focal participants. All participants volunteered as one means to fulfill a course requirement, and all were native English speakers. The age of female target participants in the final sample ranged from 18 to $44(M=20.46, S D=5.05)$. On average, participants self-reported a slightly below midpoint experience with negotiations on a 7-point scale $(M=3.22, S D=$ 1.68 ) and reported having participated on average in 5.95 negotiations $(S D=9.51)$. All participants were native English speakers.

\section{Procedure, Measures, and Materials}

After signing informed consent, participants were informed that they would be participating in two different studies, one composed of a language task that would be completed on the computer and another one that involved a mock negotiation. The tasks were completed in different rooms to emphasize the idea that the two tasks were parts of different studies and thus minimize participants' suspicion about the connection between the two. In the first phase, participants completed a response-time task (Sequential Priming Task), which was designed to measure implicit gender-negotiation stereotypes, and a brief survey designed to measure explicit gender-negotiation stereotypes. To measure explicit gender-negotiation associations, we asked participants to estimate the percentage of men and women who are strong negotiators.

In the second phase, participants were asked to take part in a mock negotiation. After the computer task was completed, participants were randomly assigned the role of either recruiter or candidate (our manipulation of the power role within the negotiation). Each dyad was then invited to sit at a conference table in a room designed to resemble a boardroom, where they prepared their negotiation strategy. The experimenter then described the task to the participants, giving general instruction as well as role-specific instructions. More specifically, the experimenter explained that the candidate has just been hired as a marketing manager and will negotiate for salary, signing bonus, vacation days, and location. The experimenter then explained to the recruiter that he or she has just hired the candidate and must negotiate in the interest of their company. The participants were instructed that their goal is to earn as many points as possible using their individual "Pay-Off Schedule." The participants received written instructions, the pay-off schedule (available in an online supplement), as well as scrap paper for preparing and taking notes. The experimenter instructed them to take $10 \mathrm{~min}$ to prepare. Participants were advised not to share their "Pay-Off Schedule" with one another.

After $10 \mathrm{~min}$, the experimenter returned and instructed the participants that they may begin the actual negotiation, which would end whenever both parties had reached an agreement, completed and signed the employment contract (available in the online supplement). Right before starting the negotiations, we asked participants about their ideal negotiation outcome. 
After reaching the agreement, participants answered a few questions about their negotiation experience, and finally they were thanked and debriefed. The study was reviewed and approved by an institutional review board of the university where data were collected for compliance with standards for the ethical treatment of human participants.

\section{Implicit Gender Stereotypes of Negotiation Counterpart}

Negotiators' implicit gender stereotypes were measured using a sequential priming task adapted from the Successful Manager Implicit Association Test (Latu et al. 2011) and the Sequential Priming Task in Latu and colleagues (Latu et al. 2015). This task measured participants' implicit associations between gender and positive negotiator traits (strong, dominant, assertive, rational, active, and effective) and negative negotiator traits (weak, submissive, accommodating, emotional, passive, and ineffective). These traits were derived from Kray and Thompson's (2004) review on gender stereotypes in negotiations. The sequential priming task was composed of 96 trials divided into two blocks. Each trial started with a fixation point in the middle of the screen, followed by a prime denoting either a male or female name, or the name of a type of building (e.g., house and cabin). The prime remained on the screen for $250 \mathrm{~ms}$, after which it was replaced by a traiteither a positive or a negative negotiator trait or a positive or negative building trait (e.g., spacious and leaky). Participants' task is to press one of the two keyboard keys to indicate, as quickly and accurately as possible, if the trait described a person or a building. Response times are measured in milliseconds using DirectRT Empirisoft software.

For analyses, mean response times for categorizing positive and negative negotiator traits after being primed with male and female names were computed. We eliminated response times that were three standard deviations above and below the mean and log-transformed the remaining response times in order to normalize the distribution of values. The final score was computed by subtracting the average response time to stereotype-consistent trials (man-good negotiator; womanbad negotiator) from those to stereotype-inconsistent trials (man-bad negotiator; woman-good negotiator). If participants more strongly associate men with good negotiators and women with bad negotiators (stereotype-consistent) compared to men with bad negotiators and women with good negotiators (stereotype-inconsistent), they should be faster to respond to the consistent compared to the inconsistent trials. Thus, higher numbers denote stronger men-good negotiator, women-bad negotiator associations.

\section{Explicit Gender Stereotypes of Negotiation Counterpart}

We asked participants to estimate the percentage of men and women who are strong negotiators in the workplace. This measure has been successfully used in previous research and tends to correlate moderately with established explicit scales (Latu et al. 2011, Latu et al. 2015) such as Hostile Sexism as measured by the Ambivalent Sexism Inventory (Glick and Fiske 2018). We computed a difference score by subtracting the estimated percentage for women from the estimated percentage for men in order to obtain a score of their explicit gender-negotiation associations. Higher (positive) numbers denote stronger explicit associations between men and negotiation competence, whereas lower (negative) numbers denote stronger explicit associations between women and negotiation competence.

\section{Negotiation Task}

Before the negotiation task started, we asked participants to fill in their ideal negotiation outcome in points ("Ideally, I would like to gain _ points in this negotiation"). The negotiation task itself was modeled after Pinkley and colleagues' (Pinkley et al. 1994). The task was a mock negotiation in which the candidate was asked to take the role of a new marketing hire, whereas the recruiter was asked to take the role of a human resources manager. Each participant's goal was to get the highest number of points, which are reflected in the PayOff Schedule.

The negotiation included four topics: salary, signing bonus, vacation days, and location. Each possible outcome was associated with a number of points. As visible in the pay-off schedule, the number of points varied for each negotiator role depending on which items would be more important to each role. Salary was a distributive negotiation outcome (win-lose: one negotiation partners' gain is the other's loss), whereas bonus and vacation days were integrative (win-win: if the candidate makes concessions on bonus and the recruiter on vacation days, both parties can maximize their points). However, the total possible number of points was the same for both recruiters and candidates. After participants reached an agreement on all topics, they filled out and signed an employment contract similar to a real-world employment negotiation. No real-life incentives were used; participants were primarily incentivized by the points they received in the game.

\section{Negotiation Performance}

We determined female participants' negotiation outcome by simply adding up the points that each participant obtained across the four negotiated items based on the employment contract they completed at the end of the negotiation. The total could range from 0 to 2000 points for both roles, with a maximum of 800 points possible to gain for salary, 1000 for signing bonus and vacation days, and 200 from location. 


\section{Results}

\section{Descriptive Statistics and Analysis Plan}

Given the dyadic nature of our data, we used Kenny's ActorPartner Interdependence Model (Cook \& Kenny 2005) that is designed to analyze data in a dyadic design. In the context of our design, this model allowed us to investigate whether female targets' negotiation performance is predicted by their counterparts' implicit and explicit gender stereotypes. As a preliminary step, we assessed the independence of the negotiating dyad members - in other words, whether the negotiation partners' implicit and explicit stereotyping scores were independent of each other. We note that although the analysis considers only the stereotyping score of the counterparts in predicting female targets' performance, stereotyping measures were collected for both dyad members. Given that the members of the dyads were distinguishable (each dyad member had a role that was not interchangeable, that is, one was the candidate and the other the recruiter), we computed a Pearson correlation coefficient to assess independence of dyad members. Consistent with Kenny's model, if scores are correlated, they are said to be non-independent and the dyad is the unit of analysis. If dyad scores do not significantly correlate, they are said to be independent and the unit of analysis can be the person. Analyses showed that candidates' and recruiters' implicit stereotyping scores were independent $(r=.02, p=.85)$. Similarly, candidates' and recruiters' explicit stereotyping scores were also independent $(r=-.11, p=.43)$. Thus, we used the person as the level of analysis in subsequent analyses.

Table 1 shows the means, standard deviations, and correlations for the variables of interest, separated by the gender of the negotiation counterpart. Given that women's ideal negotiation expectation (measured before the face-to-face negotiation) was positively and largely correlated with their negotiation performance $(r=.59, p<.0001)$, we entered women's ideal negotiation expectation as a covariate in all analyses. This strategy allowed us to investigate the predictive effects of stereotypes on women's performance within the face-to-face interaction, above and beyond women's prior expectations.

To investigate whether and when women's negotiation performance is predicted by their negotiation counterparts' implicit and explicit stereotypes, as well as their counterparts' gender and role within the negotiation, we conducted a hierarchical multiple regression analysis, with women's negotiation performance as an outcome. In the first step we entered their negotiation counterparts' implicit stereotypes (mean-centered), negotiator counterparts' explicit stereotypes (meancentered), female negotiator role (dummy coded: $0=$ candidate, $1=$ recruiter), and negotiation counterpart's gender (dummy coded: $0=$ man, $1=$ woman) as well as women's ideal negotiation expectation as a control variable. In the second step we entered all six possible two-way interactions, in the third step all four possible three-way interactions, and in the final step the four-way interaction.

Overall, the analysis revealed an $R^{2}=.54$, suggesting that these variables and their interactions explained $54 \%$ of the variance in women's negotiation performance. Importantly, results also revealed the predicted four-way interaction between counterparts' implicit stereotypes, explicit stereotypes, gender, and role in predicting women's negotiation performance $(b=-406.45, S E=174.40, p=.023)$. The addition of this interaction term explained significantly more variance $\left(\Delta R^{2}=.04, p=.023\right)$. To probe this interaction, we conducted separate analyses for female candidates $(n=40)$ and female recruiters $(n=43)$.

\section{Performance Outcomes for Female Candidates}

We first predicted that female candidates' negotiation performance would be predicted by the male (but not female) recruiters' implicit stereotypes, given their higher power within the negotiation. To investigate this hypothesis, we conducted a hierarchical multiple regression analysis with female candidates' negotiation performance as an outcome. In the first step we entered counterparts' implicit stereotypes (mean-centered), counterparts' explicit stereotypes (mean-centered), and negotiation counterparts' gender (dummy coded: $0=$ man, $1=$ woman). In the second step we entered the three two-way interactions, and in the third step we entered the three-way interaction. Although the three-way interaction was not significant $(b=155.30, S E=158.26, p=.334)$, results revealed an interaction between the counterpart's implicit stereotypes and the counterpart's gender in predicting female targets' negotiation performance $(b=17,302.90, S E=$ 7812.92, $p=.034)$. The interaction is represented in Fig. 1 . Simple slope analyses indicated that for female candidates interacting with a male recruiter, the recruiter's higher implicit gender stereotypes predicted lower performance of female candidates $(b=-17,729.21, S E=7788.25, p=.030)$. The slope was not significant when female candidates negotiated with female recruiters $(b=-426.31, S E=623.47, p=.499)$, suggesting that female candidates' performance is not influenced by their negotiation counterpart's implicit gender stereotypes when the counterpart is a woman. Recruiters' explicit gender stereotypes did not predict female candidates' negotiation performance, neither independently $(b=1.53, S E=$ $2.30, p=.512$ ) nor interactively (all $p \mathrm{~s}>.08$ ).

\section{Performance Outcomes for Female Recruiters}

We then predicted that female recruiters' negotiation performance would be predicted by the interaction of implicit and explicit stereotypes of the male (but not the female) candidates, given their low power role within the negotiation. To test this hypothesis, we analyzed negotiation performance for female 
Table 1 Descriptive statistics and correlations of study variables for female participants

\begin{tabular}{|c|c|c|c|c|c|c|c|c|c|}
\hline \multirow[b]{2}{*}{ Variables } & \multicolumn{2}{|c|}{$\begin{array}{l}\text { Women Negotiating with } \\
\text { Male Counterpart }\end{array}$} & \multicolumn{2}{|c|}{$\begin{array}{l}\text { Women Negotiating with } \\
\text { Female Counterpart }\end{array}$} & \multicolumn{5}{|c|}{ Correlations } \\
\hline & $M$ & $S D$ & $M$ & $S D$ & 1 & 2 & 3 & 4 & 5 \\
\hline 1. Implicit stereotypes of negotiation counterpart & .01 & .06 & .01 & .06 & - & -.21 & -.27 & -.23 & .44 \\
\hline 2. Explicit stereotypes of negotiation counterpart & -2.05 & 26.16 & 2.05 & 19.56 & .10 & - & $.66^{* *}$ & -.18 & -.35 \\
\hline 3. Role $(0=$ candidate, $1=$ recruiter $)$ & .65 & .49 & .48 & .50 & -.10 & -.16 & - & -.11 & -.20 \\
\hline 4. Negotiation performance for female participant & 1000.00 & 358.73 & 1095.24 & 261.31 & -.10 & .07 & -.03 & - & .23 \\
\hline 5. Ideal negotiation expectation for female participant & 1660.00 & 363.32 & 1530.95 & 424.40 & .06 & .05 & .01 & $.59 * *$ & - \\
\hline
\end{tabular}

Note. Correlations of study variables for women negotiating with a male counterpart are presented above the diagonal of the correlation matrix, and correlations for women negotiating with a female counterpart are presented below the diagonal. For negotiation performance (actual and ideal), higher numbers denote higher performance, within the possible of range of 1-2000

$* * p<.01$

recruiters by conducting a similar hierarchical multiple regression analysis as we did for female candidates. Results revealed a three-way interaction among counterparts' implicit stereotypes, counterparts' explicit stereotypes, and counterparts' gender $(b=$ $-25.01, S E=80.99, p=.004)$. The addition of this interaction term explained significantly more variance $\left(\Delta R^{2}=.12\right.$, $p=.004$ ). The interaction is represented in Fig. 2. Simple slope analyses showed that higher implicit candidate stereotypes were associated with lower female recruiter performance, but only when the candidate was a man who held low explicit gender stereotypes $(b=-9722.19, S E=3561.29, p=.010)$ (see Fig. $2 \mathrm{~b}$ ). No other slopes were significant (all $p \mathrm{~s}>.40$ ). In other words, female recruiters' performance suffered most when interacting with a male candidate who had high implicit but low explicit stereotypes. These are male negotiation counterparts who explicitly stated that women are strong negotiators, but implicitly associated them with weak negotiators.

\section{Discussion}

The goal of the present study was to investigate how explicit and implicit stereotypes held by women's negotiation counterparts predicted women's performance in an actual face-to-face salary negotiation. We also examined the role of contextual factors, such as the counterpart's gender and situational power in moderating the influence of their gender stereotypes in predicting outcomes. We proposed that women negotiators would be more likely influenced by their male compared to female counterparts' stereotypes. Regarding situational power role, we considered two competing hypotheses. First, if situational power is influential, we proposed that female candidates' negotiation outcomes would be predicted by the male (but not female) recruiters' implicit rather than explicit gender stereotypes whereas female recruiters' negotiation outcomes will be predicted by the male (but not female) candidates' explicit and implicit gender stereotypes. If, however, situational power is not influential in face-to-face negotiations, irrespective of the power role, women's negotiation performance will be predicted by their male negotiation counterparts' implicit and explicit gender stereotypes, regardless of their role.

Several findings emerged. First, the gender of negotiation counterpart played a significant role in predicting women's outcomes, such that only stereotypes coming from male negotiating counterparts, but not female ones, undermined
Fig. 1 Two-way interaction predicting female candidates' negotiation performance, as a function of recruiters' gender and implicit gender stereotypes. Implicit stereotypes are graphed at $-1 S D$ (low) and $+1 S D$ (high) above the mean. A significant slope is denoted by the black solid line (a) female recruiters with a female candidate (b) female recruiters with a male candidate

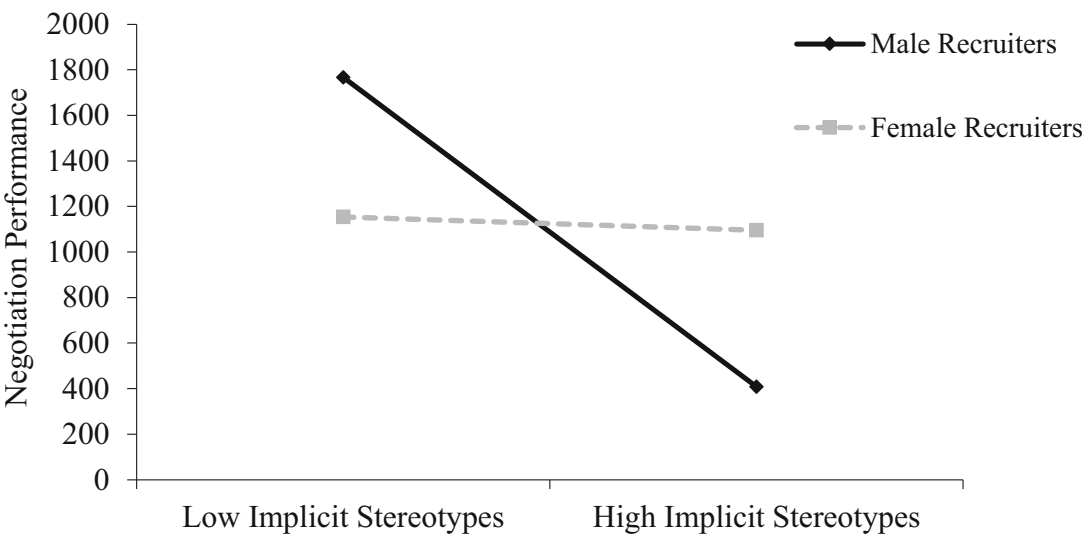


Fig. 2 Three-way interaction predicting female recruiters' negotiation performance as a function of candidates' gender as well as implicit and explicit gender stereotypes. The top panel presents the interaction for (a) female candidates; the bottom panel presents the interaction for (b) male candidates. Implicit stereotypes are graphed at $-1 S D$ (low) and $+1 S D$ (high) above the mean. A significant slope is denoted by the black solid line

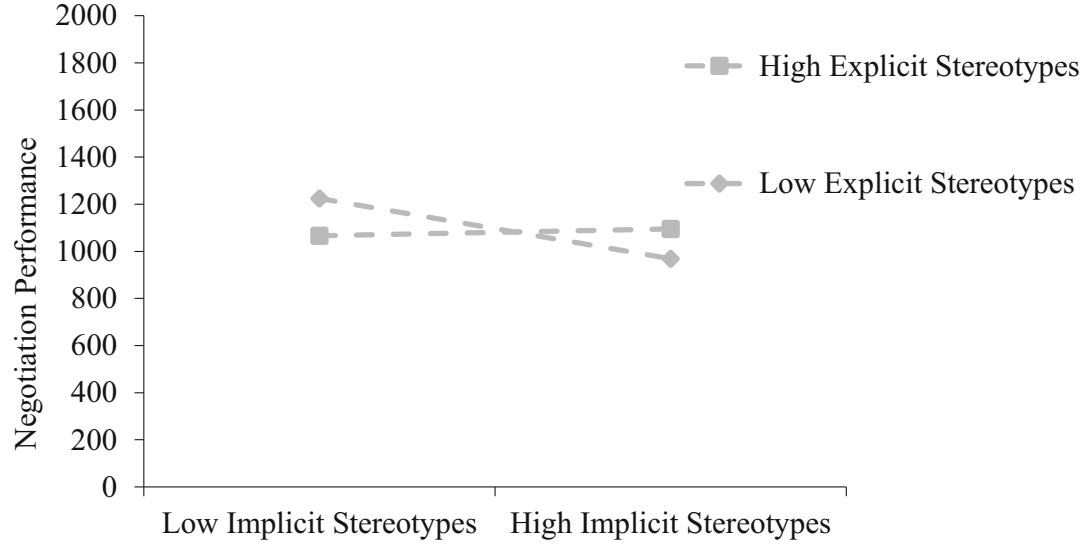

(a) Female recruiters with a female candidate

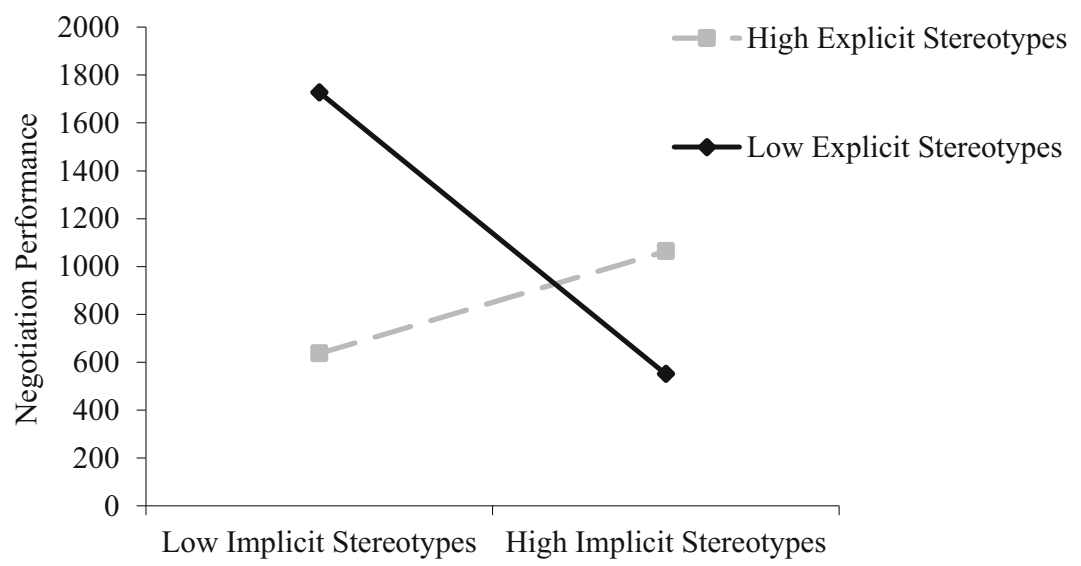

(b) Female recruiters with a male candidate women's performance. Second, the hypothesis regarding the moderating effect of situational power on the relative influence of explicit and implicit stereotypes in undermining women's performance was supported. Specifically, when male candidates negotiated with female recruiters, both implicit and explicit stereotypes held by male candidates interactively predicted outcomes for female recruiters. These findings are consistent with findings from research on mixed-gender job interviews (Latu et al. 2015), but also findings from the mixed-race interactions (Penner et al. 2010), both suggesting that the disconnect between the explicit and implicit stereotypes of interaction partners may be taxing for targets of bias, thereby reducing their performance. In the current study, male negotiator counterparts' combination of high implicit/low explicit gender stereotypes was most detrimental to female negotiators' performance. Male counterparts holding high implicit/low explicit stereotypes (i.e., those who say women are strong negotiators but implicitly associate them with weak negotiator traits) may demonstrate incongruent verbal and nonverbal signals within the face-to-face negotiation. These contradictory messages coming from their male counterparts may be stressful for female negotiators and undermine their negotiation performance.

It should be noted, however, that this pattern emerged only for the female recruiter/male candidate dyads. When the power dynamic was reversed and male negotiators were placed in a more powerful role of a recruiter, only their implicit stereotypes predicted outcomes for female candidates, such that higher implicit stereotypes of male recruiters predicted lower performance of female candidates, regardless of male recruiters' level of explicit stereotyping. These findings suggest that the situational power available to male recruiters moderated the relative influence of their implicit and explicit gender stereotypes in predicting outcomes for women-implicit stereotypes remained salient, whereas explicit stereotypes became inconsequential. These findings are consistent with research on power and stereotyping (Richeson \& Ambady 2003; Schmid \& Amodio 2017), suggesting that men's temporary power role presumably enhanced their reliance on implicit stereotypes to influence behaviors toward female negotiation counterparts. As a consequence, it was male 
recruiters' implicit, rather than explicit, gender stereotypes that predicted female targets' outcomes.

Overall our findings are important because they reveal, for the first time, the role of situational factors in determining whether and when women's negotiation performance covaries with negotiation counterparts' explicit and implicit stereotypes. Although stereotypes and power roles have been considered separately (Kray et al. 2001, Pinkley et al. 1994), to our knowledge, their interactive role was never investigated, especially in the context of gender stereotypes. The current findings suggest that regardless of women's power role in negotiations, male counterparts' implicit stereotypes can be communicated within a face-to-face negotiation and undermine women's performance. For female recruiters, this effect was further moderated by explicit stereotypes.

These findings are partially inconsistent with the findings from interracial (Penner et al. 2010) and mixed-gender (Latu et al. 2015) studies on the interactive effects of implicit and explicit stereotypes in face-to-face interactions. In these studies, non-stigmatized participant (i.e., men and Whites) presumably had greater situational power while interacting with the stigmatized participants (i.e., women and Blacks, respectively). Despite the enhanced power, it was both explicit and implicit stereotypes held by men or Whites that determined outcomes for their interaction partners and in a pattern consistent with our female recruiter/male candidate outcome. If power does in fact lead people to rely more on their automatic association rather than their explicit controlled opinions to navigate social interactions, then these studies should have demonstrated that pattern as well. In these prior studies, however, it was not just implicit stereotypes that determined group outcomes, but an interplay between both explicit and implicit stereotypes held by men or Whites.

One reason for this inconsistency may be that the power differential may not have been necessarily salient in those prior situations, whereas it became salient in our negotiation setup. Presumably, the win-lose competitive nature of the objective points-based negotiation in our study made the power differential between a recruiter and candidate more apparent. As a consequence, power was able to exert greater influence in moderating the effect of men's implicit/explicit stereotypes on women's performance. Moreover, situational power role was not directly manipulated in either of those previous studies, so it is not possible to make inferences about the causal role of situational power in moderating the role of stereotypes in faceto-face interactions based on these existing studies. The current study, however, directly investigates and documents the moderating role of situational power for women as targets as bias.

\section{Theoretical Implications}

Our findings have important implications for literature on the role of explicit and implicit stereotypes in both mixed-gender interactions. We demonstrated that explicit and implicit stereotypes determine inter-group outcomes in conjunction, but certain contextual factors may moderate their relative importance. Specifically, with regard to mixed-gender interactions in face-to-face negotiations, our study establishes that women's underperformance may be attributed to the gender stereotypes held by their male counterparts at the bargaining table. Our study also has implications for the literature on power and stereotyping because it clarifies the role of situational power in determining whether and when male counterparts' implicit and explicit stereotypes predict women's ability to claim value at the bargaining table. Although the influence of implicit and explicit gender stereotypes has been documented in face-to-face interactions such as job interviews (Latu et al. 2015), ours is the first known study to take into account the role of contextual factors in determining the exact nature of bias (explicit, implicit, or both) permeating mixed-gender interactions to influence negotiation performance. We now have an improved understanding of situations in which implicit stereotypes act alone versus act in conjunction with explicit stereotypes to predict mixed-gender outcomes.

Our study also contributes to the literature on gender differences at the bargaining table. Our findings suggest that factors outside women's control such as stereotypes and discrimination may be responsible for their underperformance in negotiations. This could, at least partly, explain the gender wage gap. Although previous work has documented that the salience of gender stereotypes can lead to lower negotiation performance for women (Kray \& Thompson 2004; Kray et al. 2001), the current study documents, for the first time, how gender stereotypes (implicit and explicit) can predict lower performance for women in face-to-face negotiations. Our findings suggest that these stereotypes can thus be communicated within the actual interaction, negatively affecting women's performance. Thus, it is not only the awareness of damaging gender stereotypes (consistent with the stereotype threat literature; Steele \& Aronson 1995), but also the face-toface communication of these stereotypes by male negotiators that predict lower outcomes for women, thus contributing to the persistent gender gap in negotiation.

\section{Practice Implications}

Identifying one of the root causes of the gender wage gap is important for practice. Given that the performance of female candidates seems to vary with male counterparts' implicit stereotypes in salary negotiations, targeted interventions to reduce men's hidden gender biases may be implemented. Certain empirically tested training programs such as the Just Say No Training (Kawakami et al. 2000) or Situational Attribution Training (Stewart et al. 2010), may be effective in reducing implicit gender bias. In terms of human resource strategy, our findings suggest that human resource staff in 
organizations should work toward reducing implicit biases rather than solely focusing on training women to be better negotiators.

We also found that stereotypes coming from female counterparts did not have performance-deterring effects. Perhaps, recruitment teams could ensure that salary negotiations are conducted between negotiators of the same gender. Because gender differences may be less salient in same-gender versus mixed-gender negotiations, the chances of negative gender stereotypes hampering women's performance may be reduced if they negotiate with women rather than men.

Many organizations rely on new employees' previous salary as a baseline to initiate salary negotiation discussions. Women are already at a disadvantage because they most commonly come to the bargaining table with lower initial salaries than men. This problem is further exacerbated at the bargaining table due to negative stereotypes associating women with ineffective negotiator traits, as our findings suggest. As a consequence, gender biases can have a cumulative longterm damaging effect throughout a women's career. To minimize the potential effect of gender stereotypes on these effects, organizations should create a clearly defined salary structure with salary scales corresponding to well-designed job descriptions. This structure ensures that salaries are objectively determined based on the amount of work and skills a job requires rather than being determined by biases that hamper women's progress within organizations.

\section{Limitations and Future Directions}

The present study utilized a human subject pool from a university. Although many U.S.-based students are employed while in college, most have not been employed in fields in which advanced negotiation skills are necessary. Therefore, one possible limitation of our study is that our experiment may have been the participants' first exposure to employment negotiations. The negotiation task was designed to account for this issue by providing instructions and assigning point values to the issues. Although this feature of our study may decrease its applicability to real-life negotiation situations where no payoff schedule with set boundaries is provided, the design helps examine the underlying mechanics of success at the bargaining table. Given the overall lack of experience, it is possible that participants viewed the task as a competitive game. Although this setup was quite motivational for students who were fully engaged in the task, and it still allows for investigating whether stereotypes can predict women's negotiation performance, it may have had an impact on negotiator's felt power and strategy. Our task was modeled after the task used by Pinkley and colleagues (Pinkley et al. 1994), but their original study had a sample of U.S. Masters-level Business students, who may have had the skills and experience necessary to ensure a real-world level of involvement in the task.
Future research should test the current study's predictions with a sample of Business students or with employees in actual organizational settings.

We were also not able to establish causation given that stereotypes were measured, not manipulated. However, our design may be more realistic and ecologically valid in that it allows us to infer how naturally occurring implicit and explicit stereotypes of interaction partners can predict objective outcomes in face-to-face negotiations.

Another limitation is that our study does not clarify whether participants' motivations at the time of self-reporting explicit bias may predict outcomes differentially. Explicit stereotypes may sometimes contradict implicit stereotypes due to two reasons: either when people are aware of their implicit biases but deliberately choose to conceal them at the time of self-reporting due to concerns about social or political correctness (i.e., social desirability) or when they are expressed by people who are genuinely unaware of their hidden biases (i.e., unawareness). It is important to make a distinction between these differential mechanisms and motivations behind selfreporting because it may help us gain a clearer understanding of how explicit stereotypes predict outcomes. For example, explicit stereotypes coming from men who willingly conceal their biases may impact women differently than those coming from men who are unaware of their hidden implicit biases. Moreover, these two may be influenced differently when men have situational power. As such, future studies should take into account how explicit stereotypes associated with naivety and deliberate concealment differentially predict outcomes for women at the bargaining table.

Also, we are still unclear about the verbal and nonverbal mechanisms associated with explicit and implicit stereotypes. Although we now know that explicit and implicit stereotypes permeate social interactions to predict outcomes, we do not know which specific behaviors or behavioral patterns are associated with each and how these behaviors subsequently predict women's performance. In their research on interracial interactions, Dovidio and colleagues (Dovidio et al. 2002) found evidence linking implicit stereotypes with nonverbal behavior and explicit stereotypes with verbal behavior. However, they did recognize limitations of their work suggesting that the spontaneity or deliberativeness of a certain behavior may be contingent upon the specific conditions under which it is elicited. Future research should therefore focus on establishing a taxonomy of behavior linking verbal/nonverbal elements with spontaneous and controlled processing within the context of salary negotiations.

\section{Conclusion}

There are many reasons that contribute to the persisting gender wage gap, some explained (e.g., occupation, sector, type of employment) and some unexplained. The current study 
uncovers one possible factor contributing to the unexplained gender wage gap: the implicit and explicit gender stereotypes that men hold within face-to-face negotiations and that can predict lower negotiation performance for women. Given the ripple effect of negotiation outcomes across women's lifetime careers, it is important to understand how and when these gender stereotypes may negatively affect women.

Acknowledgments We thank research assistants Taylur Warthen and Amber Davis for assisting with participant recruitment and data collection. We also thank Sean Duffy for providing lab space for conducting experiments for this study.

Compliance with Ethical Standards We have read and are in compliance with the guidelines of the 6th edition Publication Manual of the American Psychological Association regarding piecemeal or duplicate publication. Also, all authors, data, methods, citations, and analyses are reported truthfully and in good faith. Finally, this manuscript is not currently under review elsewhere and has not been previously published either in whole or in part. All research participants were treated in accordance with APA ethical standards.

Open Access This article is licensed under a Creative Commons Attribution 4.0 International License, which permits use, sharing, adaptation, distribution and reproduction in any medium or format, as long as you give appropriate credit to the original author(s) and the source, provide a link to the Creative Commons licence, and indicate if changes were made. The images or other third party material in this article are included in the article's Creative Commons licence, unless indicated otherwise in a credit line to the material. If material is not included in the article's Creative Commons licence and your intended use is not permitted by statutory regulation or exceeds the permitted use, you will need to obtain permission directly from the copyright holder. To view a copy of this licence, visit http://creativecommons.org/licenses/by/4.0/.

\section{References}

Amanatullah, E. T., \& Morris, M. W. (2010). Negotiating gender roles: Gender differences in assertive negotiating are mediated by women's fear of backlash and attenuated when negotiating on behalf of others. Journal of Personality and Social Psychology, 98, 256267. https://doi.org/10.1037/a0017094.

Babcock, L., \& Laschever, S. (2009). Women don't ask: Negotiation and the gender divide. Princeton, NJ: Princeton University Press.

Bargh, J. A. (1994). The four horsemen of automaticity: Awareness, intention, efficiency, and control in social cognition. Handbook of Social Cognition, 1, 1-40.

Belkin, L. Y., Kurtzberg, T. R., \& Naquin, C. E. (2013). Signaling dominance in online negotiations: The role of affective tone. Negotiation and Conflict Management Research, 6, 285-304. https://doi.org/10. 1111/ncmr.12016.

Blau, F. D., \& Kahn, L. M. (2017). The gender wage gap: Extent, trends, and explanations. Journal of Economic Literature, 55, 789-865. https://doi.org/10.1257/jel.20160995.

Bowles, H. R., \& Flynn, F. (2010). Gender and persistence in negotiation: A dyadic perspective. Academy of Management Journal, 53, 769 787. https://doi.org/10.5465/amj.2010.52814595.

Bowles, H. R., Babcock, L., \& Lai, L. (2007). Social incentives for gender differences in the propensity to initiate negotiations: Sometimes it does hurt to ask. Organizational Behavior and
Human Decision Processes, 103, 84-103. https://doi.org/10.1016/ j.obhdp.2006.09.001.

Carnevale, A. P., Smith, N., \& Gulish, A. (2018). Women can't win: Despite making educational gains and pursuing high-wage majors, women still earn less than men. Retrieved from https://cew. georgetown.edu/cew-reports/genderwagegap/.

Cook, E. P. (1994). Role salience and multiple roles: A gender perspective. The Career Development Quarterly, 43, 85-95. https://doi.org/ 10.1002/j.2161-0045.1994.tb00849.x.

Cook, W. L., \& Kenny, D. A. (2005). The actor-partner interdependence model: A model of bidirectional effects in developmental studies. International Journal of Behavioral Development, 29, 101-109. https://doi.org/10.1080/01650250444000405.

Deaux, K., \& Major, B. (1987). Putting gender into context: An interactive model of gender-related behavior. Psychological Review, 94, 369-389. https://doi.org/10.1037/0033-295x.94.3.369.

Dovidio, J. F., \& Gaertner, S. L. (2004). Aversive racism. Advances in Experimental Social Psychology, 36, 4-56. https://doi.org/10.1016/ S0065-2601(04)36001-6.

Dovidio, J. F., Kawakami, K., \& Beach, K. R. (2001). Implicit and explicit attitudes: Examination of the relationship between measures of intergroup bias. Blackwell Handbook of Social Psychology: Intergroup Processes, 4, 175-197.

Dovidio, J. F., Kawakami, K., \& Gaertner, S. L. (2002). Implicit and explicit prejudice and interracial interaction. Journal of Personality and Social Psychology, 82, 62-68. https://doi.org/10.1037/00223514.82.1.62.

Eagly, A. H., \& Karau, S. J. (2002). Role congruity theory of prejudice toward female leaders. Psychological Review, 109, 573-598. https:// doi.org/10.1037/0033-295x.109.3.573.

Fazio, R. H., \& Olson, M. A. (2003). Implicit measures in social cognition research: Their meaning and use. Annual Review of Psychology, 54, 297-327. https://doi.org/10.1146/annurev.psych.54.101601. 145225.

Fazio, R. H., \& Towles-Schwen, T. (1999). The MODE model of attitudebehavior processes. In S. Chaiken \& Y. Trope (Eds.), Dual-process theories in social psychology (pp. 97-116). New York: Guilford Press.

Fiske, S. T. (1993). Controlling other people: The impact of power on stereotyping. American Psychologist, 48, 621-628. https://doi.org/ 10.1037/0003-066x.48.6.621.

Fiske, S. T., \& Neuberg, S. L. (1990). A continuum of impression formation, from category-based to individuating processes: Influences of information and motivation on attention and interpretation. In M. Zanna (Ed.), Advances in experimental social psychology (Vol. 23, pp. 1-74). Cambridge: MA: Academic Press.

Galinsky, A. D., Gruenfeld, D. H., \& Magee, J. C. (2003a). From power to action. Journal of Personality and Social Psychology, 85, 453466. https://doi.org/10.1037/0022-3514.85.3.453.

Galinsky, A., Thompson, L., \& Kray, L. (2003b). Taking stereotypes out of stereotype threat: The effect of role-based expectations. Paper presented at the 16th annual IACM conference Melbourne, Australia. Retrieved from https://doi.org/10.2139/ssrn.399620.

Gawronski, B., \& Bodenhausen, G. V. (2006). Associative and propositional processes in evaluation: An integrative review of implicit and explicit attitude change. Psychological Bulletin, 132, 692-731. https://doi.org/10.1037/0033-2909.132.5.692.

Glick, P., \& Fiske, S. T. (2018). The Ambivalent Sexism Inventory: Differentiating hostile and benevolent sexism. Journal of Personality and Social Psychology, 70, 491-512.

Goodwin, S. A., Gubin, A., Fiske, S. T., \& Yzerbyt, V. Y. (2000). Power can bias impression processes: Stereotyping subordinates by default and by design. Group Processes \& Intergroup Relations, 3, $227-$ 256. https://doi.org/10.1177/1368430200003003001.

International Labour Organisation. (2019). Global Wage Report 2018/19: What lies behind gender pay gaps. Retrieved from https://www.ilo. 
org/wcmsp5/groups/public/\%2D\%2D-dgreports/\%2D\%2Ddcomm/\%2D\%2D-publ/documents/publication/wcms_650553.pdf.

Kawakami, K., Dovidio, J. F., Moll, J., Hermsen, S., \& Russin, A. (2000). Just say no (to stereotyping): Effects of training in the negation of stereotypic associations on stereotype activation. Journal of Personality and Social Psychology, 78, 871-888. https://doi.org/ 10.1037/0022-3514.78.5.871.

Keltner, D., Gruenfeld, D. H., \& Anderson, C. (2003). Power, approach, and inhibition. Psychological Review, 110, 265-284. https://doi.org/ 10.1037/0033-295x.110.2.265.

Koenig, A. M., Eagly, A. H., Mitchell, A. A., \& Ristikari, T. (2011). Are leader stereotypes masculine? A meta-analysis of three research paradigms. Psychological Bulletin, 137, 616-642. https://doi.org/10. 1037/a0023557.

Kray, L. J., \& Thompson, L. (2004). Gender stereotypes and negotiation performance: An examination of theory and research. Research in Organizational Behavior, 26, 103-182. https://doi.org/10.1016/ s0191-3085(04)26004-x.

Kray, L. J., Thompson, L., \& Galinsky, A. (2001). Battle of the sexes: Gender stereotype confirmation and reactance in negotiations. Journal of Personality and Social Psychology, 80, 942-958. https://doi.org/10.1037/0022-3514.80.6.942.

Latu, I. M., Stewart, T. L., Myers, A. C., Lisco, C. G., Estes, S. B., \& Donahue, D. K. (2011). What we "say" and what we "think" about female managers: Explicit versus implicit associations of women with success. Psychology of Women Quarterly, 35, 252-266. https://doi.org/10.1177/0361684310383811.

Latu, I. M., Mast, M. S., \& Stewart, T. L. (2015). Gender biases in (inter)action: The role of interviewers' and applicants' implicit and explicit stereotypes in predicting job interview outcomes. Psychology of Women Quarterly, 39, 539-552. https://doi.org/10. $1177 / 0361684315577383$.

Mazei, J., Hüffmeier, J., Freund, P. A., Stuhlmacher, A. F., Bilke, L., \& Hertel, G. (2015). A meta-analysis on gender differences in negotiation outcomes and their moderators. Psychological Bulletin, 141, 85-104. https://doi.org/10.1037/a0038184.

Miles, E. W., \& Clenney, E. F. (2010). Gender differences in negotiation: A status characteristics theory view. Negotiation and Conflict Management Research, 3, 130-144. https://doi.org/10.1111/j.17504716.2010.00054.x.

O'Neill, J. (2003). The gender gap in wages, circa 2000. American Economic Review, 93, 309-314. https://doi.org/10.1257/ 000282803321947254 .

Office for National Statistics. (2018). Understanding the gender pay gap in the UK. Retrieved from https://www.ons.gov.uk/ employmentandlabourmarket/peopleinwork/ e a r n i g s a n d w orking hours/articles/ understandingthegenderpaygapintheuk/2018-01-17\#a-breakdownof-the-gender-pay-gap.

Penner, L. A., Dovidio, J. F., West, T. V., Gaertner, S. L., Albrecht, T. L., Dailey, R. K., ... Markova, T. (2010). Aversive racism and medical interactions with black patients: A field study. Journal of Experimental Social Psychology, 46, 436-440. https://doi.org/10. 1016/j.jesp.2009.11.004.
Pinkley, R. L., Neale, M. A., \& Bennett, R. J. (1994). The impact of alternatives to settlement in dyadic negotiation. Organizational Behavior and Human Decision Processes, 57, 97-116. https://doi. org/10.1006/obhd.1994.1006.

Richeson, J. A., \& Ambady, N. (2003). Effects of situational power on automatic racial prejudice. Journal of Experimental Social Psychology, 39, 177-183. https://doi.org/10.1016/s0022-1031(02) 00521-8.

Ridgeway, C. L. (2011). Framed by gender: How gender inequality persists in the modern world. Oxford, UK: Oxford University Press.

Ridgeway, C. L., \& Diekema, D. (1992). Are gender differences status differences? In C. L. Ridgeway (Ed.), Gender, interaction, and inequality (pp. 157-180). New York: Springer.

Schmid, P. C., \& Amodio, D. M. (2017). Power effects on implicit prejudice and stereotyping: The role of intergroup face processing. Social Neuroscience, 12, 218-231. https://doi.org/10.1080/ 17470919.2016.1144647.

Spence, J. T., Helmreich, R. L., \& Stapp, J. (1974). The Personal Attributes Questionnaire: A measure of sex role stereotypes and masculinity-femininity. Journal Supplement Abstract Service, American Psychological Association. Retrieved from https://doi. org/10.1037/t02466-000.

Steele, C. M. (1997). A threat in the air: How stereotypes shape intellectual identity and performance. American Psychologist, 52, 613-629. https://doi.org/10.1037/0003-066x.52.6.613.

Steele, C. M., \& Aronson, J. (1995). Stereotype threat and the intellectual test performance of African Americans. Journal of Personality and Social Psychology, 69, 797-811. https://doi.org/10.1037/00223514.69.5.797.

Stewart, T. L., Latu, I. M., Kawakami, K., \& Myers, A. C. (2010). Consider the situation: Reducing automatic stereotyping through situational attribution training. Journal of Experimental Social Psychology, 46, 221-225. https://doi.org/ 10.1016/j.jesp.2009.09.004.

Stoker, J. I., Van der Velde, M., \& Lammers, J. (2012). Factors relating to managerial stereotypes: The role of gender of the employee and the manager and management gender ratio. Journal of Business and Psychology, 27, 31-42. https://doi.org/10.1007/s10869-011-9210-0.

Stuhlmacher, A. F., Citera, M., \& Willis, T. (2007). Gender differences in virtual negotiation: Theory and research. Sex Roles, 57, 329-339. https://doi.org/10.1007/s11199-007-9252-y.

Tellhed, U., \& Björklund, F. (2011). Stereotype threat in salary negotiations is mediated by reservation salary. Scandinavian Journal of Psychology, 52, 185-195. https://doi.org/10.1111/j.1467-9450. 2010.00855.x.

Thompson, L. L., Wang, J., \& Gunia, B. C. (2010). Negotiation. Annual Review of Psychology, 61, 491-515. https://doi.org/10.1146/ annurev.psych.093008.100458.

World Economic Forum. (2018). The global gender gap report. Retrieved from http://www3.weforum.org/docs/WEF_GGGR_2018.pdf.

Publisher's Note Springer Nature remains neutral with regard to jurisdictional claims in published maps and institutional affiliations. 